\title{
Sulphide inclusions and the age of diamond formation: Does protogeneity matter?
}

\author{
MARTHA G. PAMATO ${ }^{1}$, DAVIDE NOVELLA ${ }^{1}$, DORRIT \\ JACOB $^{2}$, BEÑAT OLIVEIRA ${ }^{3}$, D. GRAHAM PEARSON ${ }^{4}$, \\ STEPHANIE GREENE ${ }^{3}$, JUAN CARLOS AFONSO ${ }^{3}$, MARCO \\ FAVERO $^{1}$, THOMAS STACHEL ${ }^{4}$, MATTEO ALVARO ${ }^{5}$ AND \\ FABRIZIO NESTOLA ${ }^{1}$ \\ ${ }^{1}$ University of Padova \\ ${ }^{2}$ Australian National University \\ ${ }^{3}$ Macquarie University \\ ${ }^{4}$ University of Alberta \\ ${ }^{5}$ University of Pavia \\ Presenting Author: martha.pamato@unipd.it
}

Sulphides are the most abundant inclusions in diamonds and the key minerals for dating diamond formation via Re-Os isotopic analyses. A fundamental factor to consider in dating diamonds is whether the mineral inclusions formed at the same time as the diamond (syngenetic), or whether the diamonds entrapped pre-existing mineral grains (protogenetic). As recent mineralogical and geochemical studies point to a protogenetic origin of sulphides, it is important to verify whether the most commonly used decay system, ${ }^{187} \mathrm{Re}-{ }^{187} \mathrm{Os}$, is effectively reset by diffusion during encapsulation, providing thus the correct isochron age of diamond formation.

To obtain accurate chemical and age information from sulphides included in diamonds, it is critical that the sulphide and its host remained unaffected since the time of diamond formation. Also, it is essential that sulphide inclusions are well characterised in-situ before extraction in order to understand their original composition and crystallographic relationship with respect to the diamond. To this end, we investigated a suite of sulphide inclusions still entrapped in their diamond hosts from two Canadian cratons. By conducting in situ single-crystal X-ray diffraction analyses, we determined for the first time the crystallographic relationship between sulphide inclusions and diamond hosts and assess whether the sulphides are syngenetic or protogenetic. In addition, X-ray diffraction in-situ analyses allowed determination of the original monosulphide solid solution composition stable at high temperature in the mantle, indicating subsolidus conditions when encapsulated. This supports the new crystallographic evidence that indicates a protogenetic origin of the inclusions.

To confirm the ability of the Re-Os isotopic system in sulphide inclusions to date diamonds, we modelled Os chemical diffusive equilibration between a protogenetic pyrrhotite grain and a fluid/melt as a function of temperature. Our results indicate that Os exchange in sulphide inclusions with typical grain-size at mantle temperatures is very rapid. This implies that, even in protogenetic sulphides, diamond formation is likely to be reflected by Re-Os isochrons due to re-setting. 